\title{
Response to: Mean platelet volume and neutrophil-to-lymphocyte ratio in patients with Henoch-Schonlein purpura
}

\author{
Balahan Makay • Özge Altuğ Gücenmez • \\ Murat Duman · Erbil Ünsal
}

Received: 23 May 2014 / Accepted: 15 July 2014 / Published online: 2 August 2014

(C) Springer-Verlag Berlin Heidelberg 2014

We would thank for the crucial comments of our colleague Varol [1] about our article "The relationship of neutrophil-to-lymphocyte ratio with gastrointestinal bleeding in Henoch-Schonlein purpura" [2].

He drew attention to the inadequate definition of MPV measurement technique in the methods. He suggested stating the time interval between blood sampling and analysis as MPV increases over time in EDTA-anticoagulated samples. He reminded that the recommended optimal measuring time of MPV was maximum 120 min after venipuncture. The complete blood count analyses are performed in the same Coulter analyzer, which is routinely checked every month, in the central laboratory of our institution in regular intervals of $1 \mathrm{~h}$. Standard tubes with constant amount of EDTA are used. This laboratory has the ISO 15189 accreditation certificate, which enhances the reliability of our results.

He also reminded that there are significant associations of MPV with some cardiovascular risk factors such as smoking, obesity, hypertension, diabetes mellitus, hypercholesterolemia and metabolic syndrome. The mean age of the HSP patients was $6.5 \pm 2.6$ years and controls were $7.1 \pm 2.2$ years. We believe that smoking is not a prominent risk factor effecting MPV in this age group, unlike adults. We reevaluated the patients' files. The mean body mass index of our patients was not significantly different from the controls' $(16.5 \pm 2.6$ vs $17.1 \pm 1.9$, respectively, $p=0.56$ ). Besides, none of our patients and controls had hypertension. We did not measure serum glucose and cholesterol routinely in HSP patients, but urinalysis was obtained from every patient. None of the patients had glucosuria, which most likely excluded diabetes mellitus. However, we cannot comment on hyperlipidemic status of participants.

To conclude, as we indicated previously in our article, our major limitation is its retrospective setting. We once again suggest that prospective studies including larger number of patients are warranted to confirm our results.

\section{References}

1. Varol E (2014) Mean platelet volume and neutrophil-to-lymphocyte ratio in patients with Henoch-Schonlein purpura. Rheumatol Int. doi:10.1007/s00296-014-3021-3

2. Makay B, Gücenmez OA, Duman M, Unsal E (2014) The relationship of neutrophil-to-lymphocyte ratio with gastrointestinal bleeding in Henoch-Schonlein purpura. Rheumatol Int. doi:10.1007/s00296-014-2986-2

This comment refers to the article available at doi:10.1007/s00296-014-3021-3.

B. Makay $(\bowtie) \cdot$ Ö. A. Gücenmez · E. Ünsal

Division of Rheumatology, Department of Pediatrics, Dokuz

Eylül University Hospital, 35340 Balçova, Izmir, Turkey

e-mail: balahan.bora@deu.edu.tr

\section{Duman}

Division of Emergency Care, Department of Pediatrics, Dokuz

Eylül University Hospital, 35340 Balçova, Izmir, Turkey 